\title{
Apertura comercial y crecimiento económico de largo plazo
}

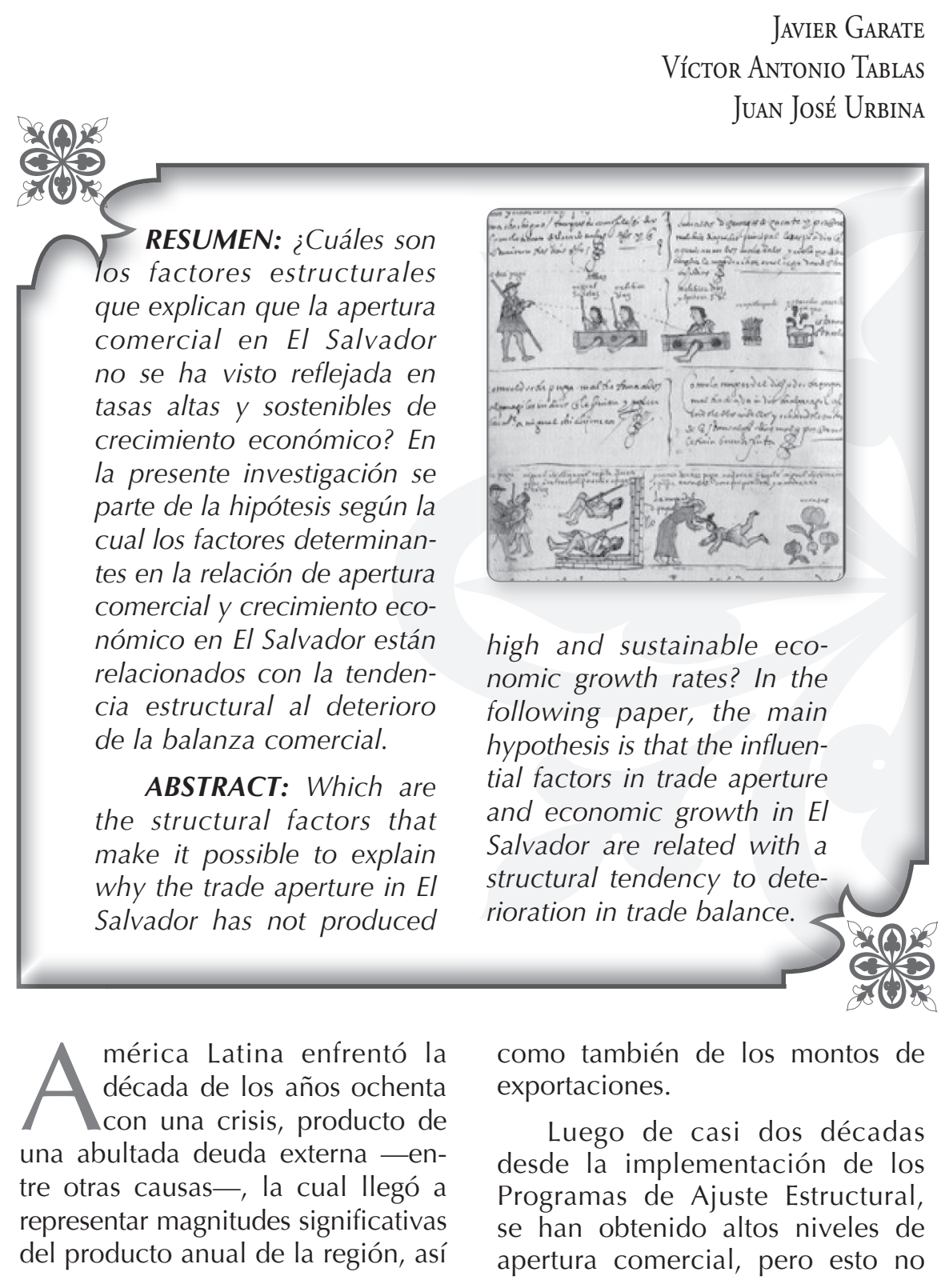


se ha traducido en un panorama macroeconómico que refleja tasas de crecimiento altas y sostenidas, además de enfrentarnos a un déficit creciente de balanza comercial.

Es por ello que surge la interrogante: ¿Cuáles son los factores estructurales que explican que la apertura comercial en El Salvador no se ha visto reflejada en tasas altas y sostenibles de crecimiento económico? En la presente investigación se parte de la hipótesis según la cual los factores determinantes en la relación de apertura comercial y crecimiento económico en El Salvador están relacionados con la tendencia estructural al deterioro de la balanza comercial.

Para someter a prueba nuestra hipótesis, realizaremos un análisis de la relación existente entre la apertura comercial y el crecimiento económico de El Salvador, en el período comprendido entre los años 1989 y 2007. El análisis se realizó utilizando un enfoque estructural, cuyo fin es determinar los factores fundamentales de largo plazo que restringen que la relación positiva entre crecimiento económico y apertura comercial se cumpla para el caso de El Salvador.

Este trabajo se divide en tres partes. En la primera, utilizamos la ley de Thirlwall, que, desde una perspectiva estructural, busca explicar el crecimiento económico convergente o divergente en el largo plazo. Dedicamos la segunda parte a caracterizar el proceso de liberalización y apertura comercial promovido en El Salvador durante el período de 1989 a 2007. El último capítulo se enfoca en el análisis de la relación entre apertura comercial y crecimiento económico en el caso de El Salvador. Posteriormente, se presenta un apartado de conclusiones generales obtenidas durante el proceso de investigación.

\section{Desempeño macroeconómico de \\ El Salvador: comercio internacional e ingreso en los años de 1960 a 2007}

Desde una perspectiva de largo plazo, podemos decir que El Salvador ha transitado por diferentes etapas de crecimiento económico, caracterizadas por una fuerte influencia de los mercados externos. En este apartado se examinan algunos indicadores macroeconómicos que posibilitan observar tal influencia. Para ello, destacamos con especial énfasis el período que comprende desde el inicio de la década de los noventa y finaliza en el año 2007, por ser este en el que ha tomado lugar el proceso de apertura comercial de El Salvador.

\subsection{Grado de apertura comercial}

Para evidenciar que las últimas medidas de política comercial implementadas en el país han efectivamente conllevado a un mayor nivel de apertura comercial, nos enfocamos en examinar el Índice de Apertura Comercial (IAC), defi- 
nido como la razón entre la suma de exportaciones e importaciones a precios corrientes y el PIB nomi-

nal $\left(\frac{\mathrm{X}+\mathrm{M}}{\mathrm{PIB}}\right)\left(\frac{\mathrm{X}+\mathrm{M}}{\mathrm{PIB}}\right)$. Dicho indicador no corresponde en su totalidad al grado de apertura de los mercados de un país, sino más bien, al grado de interacción que la economía, en este caso la de El Salvador, posee con el resto de socios comerciales. La evolución del IAC se muestra en el gráfico siguiente:

\section{Gráfico 1: Grado de apertura comercial calculado con valores}

nominales 1960-2007

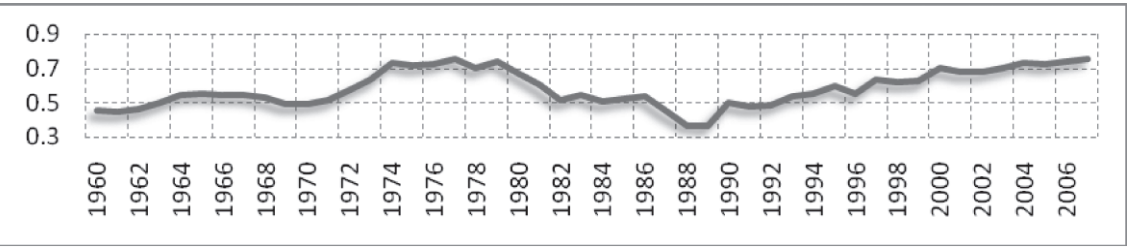

Fuente: Elaboración propia con base a información del BM: World Development Indicators y BCR de El Salvador.

Históricamente en El Salvador existe una tendencia a que los volúmenes de transacciones comerciales con el resto de países socios del mundo representen una muy grande proporción del ingreso, incluso para los años comprendidos entre 1960 y 1979, años en que la economía salvadoreña se caracterizó por un alto grado de proteccionismo, como parte del modelo ISI. El mencionado período registró en un comienzo un grado de apertura comercial cercano a 0.45 , con una tendencia al alza para los años siguientes, la cual llevó a que en el cierre del mismo período se registrara aproximadamente un grado de apertura de 0.74. Dicho de otra manera, los volúmenes de transacciones comerciales que el país sostuvo con el resto del mundo, representaron aproximadamente el $45 \%$ y $74 \%$ del PIB de esa época respectivamente.
No obstante, en la casi totalidad de la comúnmente denominada "década perdida" se observó un notorio decaimiento del grado de apertura comercial, al pasar de un índice de cerca del $67 \%$ en el año 1980 , a un $37 \%$ en 1989 , cifra registrada como la más baja en El Salvador durante el último cincuentenario, debido en gran medida al conflicto armado vivido en el país.

A partir de 1990, con la llegada de un nuevo gobierno, sumado a la finalización del conflicto armado, se inició un crecimiento sostenido de dicho índice, el cual mostró una acelerada recuperación desde un comienzo, al registrar un grado de apertura de aproximadamente 50\% en 1990 y cerca de $75 \%$ en el año 2007.

Recordemos que en los noventa, las medidas de apertura -como 
se expuso en el Capítulo II- fueron llevadas a cabo como parte de los requisitos establecidos por los $\mathrm{PAE}$, los cuales promovían esta estrategia como medio para impulsar un crecimiento económico sostenido en el largo plazo, ideario que se convirtió en la rúbrica de los organismos internacionales que la promulgaban. Ejemplo de ello es la frase que se presenta a continuación.

"Los hechos demuestran que para experimentar un crecimiento sostenido, la economía debe estar abierta al comercio y la inversión con el resto del mundo (...) En promedio, los países en desarrollo que recortaron drásticamente los aranceles durante los años ochenta crecieron a un ritmo más fuerte que los demás en la década siguiente" (FMI, 2001)

Acatando las recomendaciones de dicho discurso, El Salvador se embarcó en el proyecto de apertura comercial en 1989, lo cual -como demuestra el gráfico 1- ciertamente incrementó los volúmenes de transacciones comerciales con el resto del mundo, incremento que fue potenciado en cierta medida debido a nuestro acercamiento y/o fortalecimiento de relaciones con algunos socios comerciales, como lo son Chile, República Dominicana, México y Estados Unidos, el último nuestro principal socio comercial.

\subsection{Crecimiento económico y evolución de exportaciones e im- portaciones}

De forma general, destacamos tres períodos de características económicas y sociales muy parti- culares en El Salvador: el período caracterizado por el modelo ISI, comprendido entre 1950 y 1979 , el de conflicto armado interno, que de forma más intensa duró de 1980 a 1989, y el de implementación de la economía de mercado vigente desde principios de 1989. Con base a ello, examinamos el comportamiento revestido por la economía salvadoreña $n$ esos períodos ${ }^{1}$. En lo que respecta a la producción, El Salvador mostró elevadas tasas de crecimiento en los años de 1960 a 1979 -en particular mayores al inicio de ese período-, época de alto proteccionismo, en la cual además se registró una tasa de crecimiento muy favorable para las exportaciones en comparación a las importaciones, tal como se muestra en la tabla siguiente:

Tabla 1: Tasas anuales medias de crecimiento del PIB, exportaciones e importaciones de El Salvador en decenios ${ }^{2}$

\begin{tabular}{|l|c|c|c|c|c|}
\hline & $\mathbf{1 9 6 0 - 1 9 6 9}$ & $\mathbf{1 9 7 0 - 1 9 7 9}$ & $\mathbf{1 9 8 0 - 1 9 8 9}$ & $\mathbf{1 9 9 0 - 1 9 9 9}$ & $\mathbf{2 0 0 0 - 2 0 0 7}$ \\
\hline PIB & $5.3 \%$ & $3.6 \%$ & $-0.9 \%$ & $4.4 \%$ & $2.5 \%$ \\
\hline Exportaciones & $8.1 \%$ & $6.1 \%$ & $-5.5 \%$ & $10.6 \%$ & $4.0 \%$ \\
\hline Importaciones & $3.7 \%$ & $6.8 \%$ & $-2.3 \%$ & $9.9 \%$ & $4.5 \%$ \\
\hline
\end{tabular}

Fuente: Elaboración propia con base a información del BM: World Development Indicators y BCR de El Salvador. 
Por otro lado, en la "década perdida" se registraron tasas de variación negativas para el PIB y para los volúmenes de exportaciones e importaciones medidos a precios constantes, lógicamente en mayor medida influenciadas por el conflicto armado que el país vivió.

Luego, en lo que respecta al período que va de 1990 a 1999, se muestra un crecimiento económico como producto de factores internos y externos. Entre los primeros destacamos la reconstrucción luego del conflicto y la recuperación del consumo reprimido, apoyado por el auge de las remesas. Como segundo factor, se encuentra el aumento de aproximadamente $4 \%$-en promedio- de los términos de intercambio internacionales para los años comprendidos entre 1991 y 1995 (BM, 2003). El resultado sin embargo, no se reflejó de la misma forma en el período comprendido de 2000 a 2007, ya que solamente se registró una tasa media anual de crecimiento de aproximadamente $2.5 \%$, lo que es cerca del $43 \%$ menor que la de la década pasada (ver Tabla 5).

Las tasas de variación positivas para el PIB, exportaciones e impor- taciones, es un resultado que por un lado parece favorable - por obvias razones - pero que por otro pone en cuestión los discutidos beneficios de la apertura comercial, ya que dejando de lado los años comprendidos entre 1991 y 1994, las tasas de crecimiento económico del período de liberalización y apertura, no equiparan ni superan en su mayoría a las obtenidas en los años sesenta y setenta, años de predominio del modelo $\mid \mathrm{SS}^{3}$.

Por otro lado, resulta importante destacar que nos interesa conocer el comportamiento del crecimiento económico de largo plazo de El Salvador en relación con el de las economías del resto del mundo. Como se dijo en capítulos previos, el desempeño de un país dado está en buena medida influenciado por el desempeño de otros países, por lo que tomando en consideración que Estados Unidos es nuestro principal socio comercial, es para fines de este estudio utilizado como proxy del desempeño del resto del mundo. Con base a ello, la evolución de las tasas de crecimiento de ambos países se muestra a continuación: 


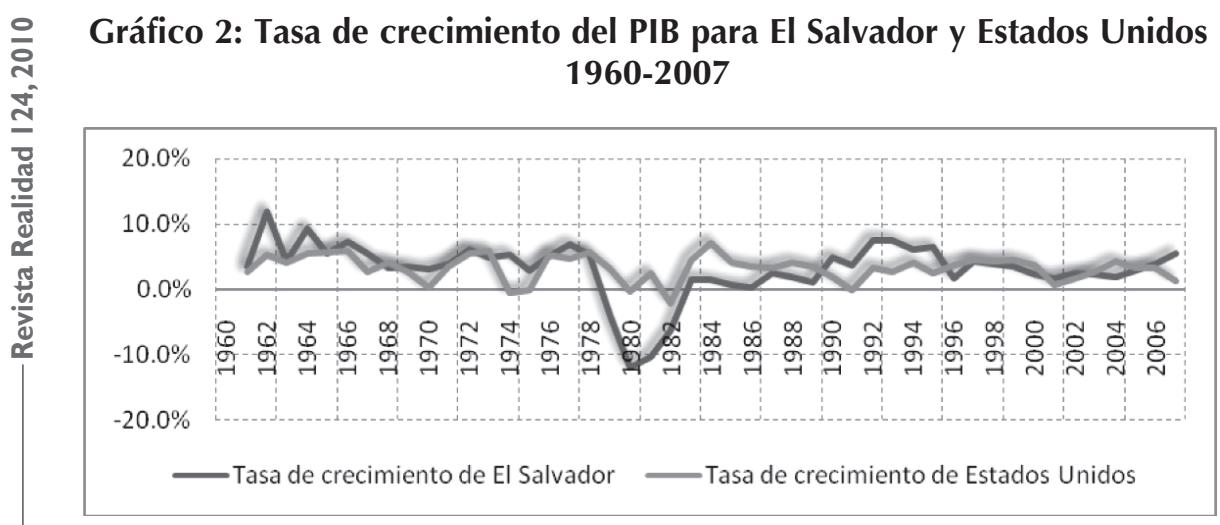

Fuente: Elaboración propia con base a información del BM: World Development Indicators y BCR de El Salvador.

La relación histórica que se observa entre el crecimiento económico de El Salvador y Estados Unidos parece compartir un determinado patrón de comportamiento en su tendencia. Según se aprecia en el gráfico 2, en ciclos de desaceleración de la economía estadounidense, El Salvador ha respondido en la misma dirección y viceversa. De lo anterior, resulta de interés cuantificar dicho efecto. Por ello, utilizamos el coeficiente de correlación de Pearson, definido como $\rho=\frac{\operatorname{cov}(Y, W}{\sigma_{\mathrm{y}} \sigma_{W}} \rho=\frac{\operatorname{Cov}\left(Y_{W},\right.}{\sigma_{\mathrm{Y}} \sigma_{W}}$, del cual se obtiene una correlación lineal estadísticamente significativa de la tasa de crecimiento de ambos países ${ }^{4}$, contrastada con un valor crítico del $5 \%$, dando como resultado un valor positivo de aproximadamente 0.416 de rho, constatando lo antes dicho.

Acevedo (citado en Solórzano, 2008) al referirse al inicio de la actual recesión de Estados Unidos, señala que "los canales de transmisión de dicha crisis económica hacía El
Salvador serán a través de las exportaciones y las remesas familiares". Esto refleja que las recesiones en las economías de nuestros principales socios comerciales afectaran significativamente nuestro desempeño económico en el largo plazo, dado que ellas influyen de manera directa en la demanda, la cual, como lo retoma Thirlwall de Keynes, es el factor dinamizador del crecimiento económico.

\subsection{El rumbo de los saldos comer- ciales}

En lo que concierne a los saldos comerciales de bienes y servicios, existió una tendencia oscilante entre valores positivos y negativos de los mismos hasta el año de 1980, saldo que en general se mantuvo inclinado a favor del déficit, sin ser este muy agravado. No obstante, el año siguiente fue el inicio de un consistente y creciente déficit de balanza comercial, como se aprecia en el gráfico presentado a continuación: 
Gráfico 3: Saldo de balanza comercial 1960-2007

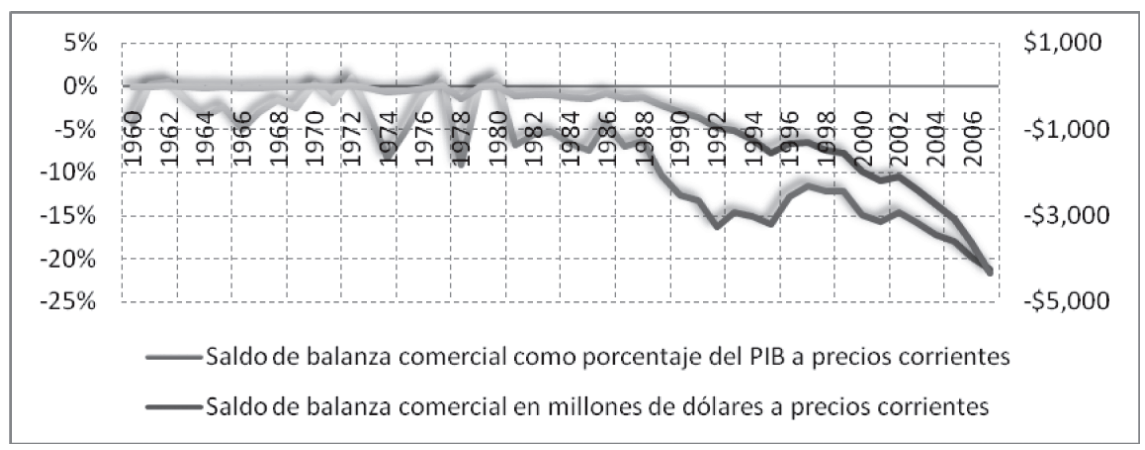

Fuente: Elaboración propia con base a información del BM: World Development Indicators y BCR de El Salvador.

Los saldos deficitarios manifestaron un repunte en la transición de 1988 a 1989, con cifras que alcanzaron los $\$ 457$ millones y $\$ 608$ millones, equivalentes al $6.5 \%$ y $10.5 \%$ del PIB de la época, respectivamente. Posterior a 1989 , los saldos comerciales continuaron siendo negativos con cifras porcentuales -relativas al PIB- que se mantuvieron en los dos dígitos, Ilegando al $15 \%$ en el año 2000 y al $21.2 \%$ en el 2007.

Evidentemente, el proceso de liberalización comercial puesto en marcha en el país ha propiciado el incremento de los flujos de exportaciones e importaciones de bienes y servicios. Sin embargo, no ha conseguido el mismo éxito en lo que respecta al aminoramiento del déficit comercial que empezó a cobrar fuerza en los años ochenta. Más bien, en forma contraria, ha desencadenado una tendencia continua y aún mayor a registrar saldos de balanza comercial deficitarios.
Recapitulando brevemente, hemos visto que el período de apertura comercial registra tasas de crecimiento económico positivas. Sin embargo, no han sido superiores a las registradas en el período caracterizado por el proteccionismo, a esto se suma que los saldos comerciales fueron mucho más favorables en ese entonces.

\section{Estimación econométrica de las elasticidades ingreso de importaciones y exportaciones}

Existe una larga tradición de la literatura económica en lo que concierne al estudio del crecimiento económico relacionado y convergente entre naciones, especialmente por el lado del análisis neoclásico. No obstante, en este estudio utilizamos la perspectiva poskeynesiana, la cual, con los planteamientos básicos y tradicionales de la ley de Thirlwall, brinda cabida a abordar dicha temática con un enfoque de 
tipo estructural. Esto es así, porque el modelo permite, por medio del estudio del ratio de elasticidades ingreso de exportaciones e importaciones, entender el comportamiento de la estructura exportadora e importadora de El Salvador y así por consecuencia entender también el desempeño del crecimiento económico de nuestro país en relación con los demás países del mundo como resultado de nuestra liberalización y apertura comercial.

\subsection{Metodología utilizada}

La realización del análisis empírico de la ley de Thirlwall requirió del planteamiento de algunos supuestos fundamentales, como lo es la existencia de una capacidad ilimitada de la oferta, por lo que el volumen de exportaciones e importaciones está determinado por el lado de la demanda. Además, se asume que los bienes producidos en El Salvador y Estados Unidos no poseen características que los conviertan en sustitutos perfectos.

El cálculo de la estimación de las elasticidades de demanda de importaciones y exportaciones se efectúa a través de la determinación de las funciones de exportaciones e importaciones planteadas en el Capítulo I, tal como se detallan a continuación:

Función de importaciones:

[8]

$$
M=\beta\left(\frac{P_{f} \xi}{P_{A}}\right)^{0} Y^{\xi} M=\beta\left(\frac{P_{f} \xi}{P_{A}}\right)^{0} Y^{\xi}
$$

Función de exportaciones
[9]

$X=\alpha\left(\frac{P_{A}}{P_{f} s}\right)^{\eta} W^{\pi} X=\alpha\left(\frac{P_{A}}{P_{f} s}\right)^{\eta} W^{\pi}$

Siguiendo los procedimientos estándares, aplicamos logaritmo natural a la función [8] y [9], y con ello se obtienen las ecuaciones siguientes:

[10.1]

$\ln M_{t}=\ln \beta_{0}+\sigma_{t} \ln \left(P_{f_{t}}-P_{d_{t}}+\theta_{t}\right)+\xi_{t} \ln Y_{t}+u_{t}$ $\ln M_{\mathrm{t}}=\ln \beta_{0}+\sigma_{\mathrm{t}} \ln \left(P_{f_{\mathrm{t}}}-P_{d_{\mathrm{t}}}+\theta_{\mathrm{t}}\right)+\xi_{\mathrm{t}} \ln Y_{\mathrm{t}}+u_{\mathrm{t}}$

[10.2]

$\ln X_{\mathrm{t}}=\ln \alpha_{0}+\eta_{\mathrm{t}} \ln \left(P_{\dot{d}_{\mathrm{t}}}-P_{f_{\mathrm{t}}}-e_{\mathrm{t}}\right)+\pi_{\mathrm{t}} \ln W_{\mathrm{t}}+v_{\mathrm{t}}$ $\ln X_{\mathrm{t}}=\ln \alpha_{0}+\eta_{\mathrm{t}} \ln \left(P_{d_{\mathrm{t}}}-P_{f_{\mathrm{t}}}-\varepsilon_{\mathrm{t}}\right)+\pi_{\mathrm{t}} \ln \omega_{\mathrm{t}}+v_{\mathrm{t}}$

Las variables que conforman estas ecuaciones están expresadas en función del tiempo, con ello en mente, la variable $M_{t} M_{t}$ en la ecuación [10.1] representa el volumen de importaciones del país local expresado en dólares a precios constantes, $\emptyset_{t} \varrho_{t}$ simboliza la elasticidad precio de demanda de importaciones.

Además, $P_{f_{t}} P_{f_{t}}$ y $P_{d_{t}} P_{d_{t}}$ representan los índices de precios del resto del mundo y de la economía local respectivamente; la variable $e_{t} \varepsilon_{t}$ simboliza el tipo de cambio nominal. En conjunto, estas tres variables conforman el tipo de cambio real.

La variable $\xi_{t} \xi_{t}$, como se mencionó en el Capítulo I, simboliza la elasticidad ingreso de demanda de importaciones, mientras que la variable $Y_{t} Y_{t}$ representa el PIB de la 
economía local expresando en precios constantes, y $u_{t} u_{t}$ simboliza las perturbaciones de los errores.

La ecuación [10.2] especifica como variable endógena al logaritmo natural de $X_{\mathrm{t}} X_{\mathrm{t}}$, esta misma expresada en nivel, representa el volumen de exportaciones del país local al resto del mundo medido en unidades de moneda local a precios constantes. Las variables $\eta_{t} \eta_{t}$ y $\pi_{t} \pi_{t}$ simbolizan la elasticidad precio de demanda exportaciones y la elasticidad ingreso extranjero de demanda de exportaciones respectivamente, $W_{t} W_{t}$ se utiliza en representación del ingreso del resto del mundo, que de igual forma es medido a precios constantes, la variable $v_{t} v_{t}$ denota los residuos entre los valores observados y los ajustados, también conocido como perturbaciones, y finalmente, $\alpha_{0} \alpha_{0}$ y $\beta_{0} \beta_{0}$ son los interceptos de sus correspondientes ecuaciones.

Con respecto a los datos utilizados, es de suma importancia tener en cuenta que las exportaciones e importaciones de bienes y servicios, el ingreso de El Salvador y del resto del mundo, en este caso Estados Unidos, fueron trabajados a precios constantes del año 1990.

En relación a la tasa de cambio real, se tomaron los índices de precios de El Salvador y Estados Unidos, ambos también con base 1990, mientras que el tipo de cambio nominal fue asumido como unitario tal y como se muestra en Thirlwall (2003).
Las funciones [10.1] y [10.2] son utilizadas para la estimación de las elasticidades ingreso de exportaciones e importaciones por medio de ecuaciones de cointegración, las cuales en su presencia reflejan la existencia de un equilibrio de largo plazo entre las variables involucradas, el método del que nos auxiliamos en este caso es el propuesto por Soren Johansen.

Para ejecutar el método de cointegración de Johansen fue necesario primero tomar en consideración las potenciales propiedades no estacionarias de las series temporales, por lo que se realizó pruebas de raíces unitarias Dickey-Fuller aumentada para el PIB de ambos países, las exportaciones, importaciones y para el tipo de cambio real, todas expresadas en logaritmo natural, de lo que se obtuvo que en su totalidad mostraron no ser estacionarias en nivel, pero si en su primera diferencia, con ello se puede decir que estas son integradas de orden uno, o dicho de otra forma, representan un proceso I(1) en nivel y sus primeras diferencias los son de orden cero ó $\mathrm{I}(0)$.

El siguiente paso consistió en la especificación de modelos de vectores autorregresivos (VAR) para las funciones [10.1] y [10.2], que brindaron a través de los criterios de información de Schwarz (SC), Akaike $(\mathrm{AIC})$, relación de verosimilitud (LR) y Hannan Quinn (HQ), los rezagos óptimos a ser utilizados para la cointegración de las ecuaciones de importaciones y exportaciones, 
así, del resultado de dichas pruebas se desprende el uso de dos y tres rezagos respectivamente ${ }^{5}$. Hecho lo anterior, se pasó a constatar la existencias de ecuaciones de cointegración a través de las pruebas de Trazas y de Máximo Valor Propio, las cuales señalaron la existencia de al menos un vector cointegrante para las funciones de exportaciones e importaciones.

Estimación y estudio de las elasticidades ingreso de demanda de exportaciones e importaciones

La elasticidad ingreso de demanda de exportaciones es formalmente definida como $\pi=\frac{\Delta X}{X} \cdot \frac{W}{\Delta W}$ $\pi=\frac{\Delta X}{X} \cdot \frac{W}{\Delta W}$, expresión que denota el cambio porcentual que sufre el volumen de exportaciones provenientes del país local, ante un cambio ceteris paribus de una unidad porcentual del ingreso del resto del mundo. De forma similar, la elasticidad ingreso de demanda de importaciones es expresada como $\xi=\frac{\Delta M}{M} \cdot \frac{Y}{\Delta Y} \xi=\frac{\Delta M}{M} \cdot \frac{Y}{\Delta Y^{\prime}}$ dicho término

Tabla 2: Elasticidades ingreso de exportaciones e importaciones y tasas medias de crecimiento de El Salvador y Estados Unidos para el período de pre-apertura y para el de liberalización y apertura

\begin{tabular}{|l|c|c|c|c|c|c|}
\hline & $\pi$ & $\varepsilon$ & $\begin{array}{c}\text { Razón de } \\
\text { elasticidades }\end{array}$ & $\begin{array}{c}\text { Tasa de } \\
\text { crecimiento } \\
\text { El Salvador }\end{array}$ & $\begin{array}{c}\text { Tasa de } \\
\text { crecimiento } \\
\text { EUA }\end{array}$ & $\begin{array}{c}\text { Razón de } \\
\text { tasas de } \\
\text { crecimiento }\end{array}$ \\
\hline $\begin{array}{l}\text { Período de pre- } \\
\text { apertura (1960-1978) }\end{array}$ & 1.94 & 1.39 & 1.40 & $5.1 \%$ & $3.6 \%$ & 1.41 \\
\hline $\begin{array}{l}\text { Período de } \\
\text { liberalización y } \\
\text { apertura (1989-2007) }\end{array}$ & 2.67 & 2.42 & 1.11 & $3.7 \%$ & $2.7 \%$ & 1.36 \\
\hline
\end{tabular}

Fuente: Elaboración propia a través del uso de los métodos de cointegración de Johansen con base a información del BM: World Development Indicators y BCR de El Salvador. a manera ceteris paribus denota el cambio porcentual del volumen de importaciones efectuado por el país local, ante el cambio de una unidad porcentual del ingreso de la misma.

Formulado lo anterior y previo al cálculo de las elasticidades, resulta importante reiterar que el período de liberalización y apertura de los mercados comenzó en El Salvador en el año de 1989, con lo que se dejó atrás el proteccionismo que se había instaurado desde la época de predominio de la ISI. Por ello, en nuestras estimaciones buscamos comparar dos períodos ${ }^{6}$ : el comprendido entre 1960 y 1978 que nosotros denominamos de pre-apertura, retomado con el afán de contrastarlo con el período de nuestro interés, comprendido por los años de 1989 a 2007, el cual denominamos de apertura y liberalización.

La estimación de las elasticida$\operatorname{des}^{7}$ obtenidas para ambos períodos se detalla a continuación: 
Según los resultados obtenidos, en el período de preapertura la elasticidad ingreso de la demanda de exportaciones fue de 1.94, valor que supera considerablemente a la elasticidad de importaciones, la cual se estimó con un valor de sólo 1.39 .

Estos coeficientes indican que la demanda de exportaciones se mostró más elástica que la demanda de importaciones, es decir que los estadounidenses estuvieron más dispuestos a incrementar los volúmenes de importaciones adquiridos -nuestras exportaciones- cuando su PIB experimentó aumentos, que los consumidores de El Salvador a demandar bienes producidos en Estados Unidos en circunstancias similares. Este resultado según lo establecido por la función [7] o ley de Thirlwall, señala que en términos de la tendencia de crecimiento de largo plazo, la economía salvadoreña creció con más fuerza que la economía de Estados Unidos en todo el período, condición que puede ser percibida en el Gráfico 2.

La elasticidad de exportaciones aumentó en cerca de $38 \%$ en lo que ha transcurrido del período de liberalización y apertura, registrando un valor de 2.67, sin embargo, la elasticidad ingreso de importaciones también aumentó, esta variación fue de aproximadamente $74 \%$, lo que da como resultado que en la comparación de elasticidades, el valor de $\pi \pi$ sea únicamente un $10 \%$ mayor al de $\xi \xi$, al ser este último de 2.42. La brecha de elasticidades antes mencionadas ha variado desfavorablemente en el período de apertura y liberalización comercial, separándose únicamente por un 0.25 (diferencia entre 2.67 y 2.42), mientras que en el período de pre-apertura esta separación era de 0.55 (diferencia entre 1.94 y 1.39).

Con ello se plantea que el período de apertura y liberalización muestra, en comparación al período de pre-apertura, un cierre de la brecha entre los valores de las elasticidades ingreso de exportaciones e importaciones, y así el cálculo del ratio de elasticidades arroja un valor muy ligeramente superior a la unidad. En consecuencia, acorde a la ley de Thirlwall, la economía salvadoreña permanece creciendo a tasas generales mayores que las de Estados Unidos, tasas de crecimiento relativas que, sin embargo, no logran equiparar en su mayor parte a las sostenidas en el período de pre-apertura.

Es entonces, que la implementación del proyecto de apertura comercial en el país ha traído consigo una disminución del ratio de elasticidades ingreso, razón por la que ahora pasamos a examinar la evolución de los valores de $\pi \pi$ y $\xi \xi$ a lo largo de dicho período. Para ello realizamos la estimación utilizando una vez más el método de cointegración de Johansen, y basándonos en la metodología empleada por Moreno-Brid (2003). Tal metodología consiste en estimar el 
valor de las elasticidades en cada uno de los años recientes tomando intervalos temporales compuestos por treinta años previos, las iteraciones comienzan por 1960-1989 y finalizan con 1978-2007, de lo que se estimaron los valores de elasticidades con los que se construyó el gráfico siguiente:

\section{Gráfico 4: Elasticidad ingreso de la demanda de exportaciones e importaciones 1989-2007 (iteraciones con $n=30$ )}

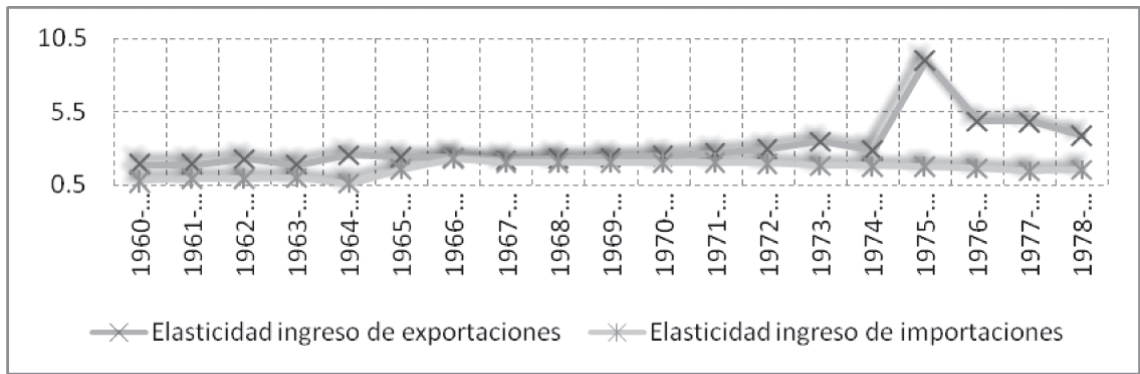

Fuente: Elaboración propia, a través del uso de los métodos de cointegración de Johansen con base a información del BM: World Development Indicators y BCR de El Salvador.

En el gráfico 4 se muestra que ambas elasticidades se mantienen relativamente estables a lo largo del período de apertura y liberalización comercial. La brecha de elasticidades es favorable en el sentido que $\pi$ $\pi$ supera a $\xi \xi$ y nos permite crecer más que nuestro principal socio comercial. Sin embargo, no es lo suficientemente amplia para que las tasas de crecimiento sean considerablemente mayores. Por su parte, se distinguen dos momentos en que esta brecha resulta ser amplia: 1989-1994 y 2002-2007, brechas que son congruentes al acelerado crecimiento de la reconstrucción luego del conflicto armado en El Salvador y a la crisis de especulación inmobiliaria en Estados Unidos respectivamente. Esta última brecha se comporta de esa manera debido a que, teniendo una fuerte relación comercial con los norteamericanos, la burbuja especulativa que les aquejaba influyera en nuestra economía de manera positiva desde un principio, hasta el punto que dicha burbuja explotara y la brecha antes mencionada tendiera a disminuirse. Resta por destacar que en el período intermedio de 1995-2001, la brecha de elasticidades se vio disminuida hasta el punto de casi volverse nula. En los últimos años la distancia entre las mismas se ha visto incrementada, por lo que podría llegar a repetirse lo observado en 1995-2001, basándonos en las tendencias de las elasticidades observadas en 2006 y 2007.

Por su parte, podemos mencionar nuevamente que mientras mayor sea la brecha de la elasticidad ingreso de la demanda de las ex- 
portaciones y la elasticidad ingreso de la demanda de importaciones -siendo superior la primera-, mayor será nuestra tasa de crecimiento con respecto a la de nuestros principales socios comerciales. Es por lo anterior que al observar su posible tendencia a la convergencia entre sí para el futuro, resulta relevante descubrir la forma en que se les puede afectar a nuestro favor.

\subsection{Análisis de los factores que in- fluyen en la razón de elasticidades en el período de apertura y libera- lización en El Salvador}

En este apartado se ofrecen breves explicaciones a las razones estructurales del deterioro de la ratio de elasticidades en el período de apertura en El Salvador, lo que nos da ideas sobre la situación del comercio del país, para así con ello determinar la dirección que las políticas económicas de carácter estructural podrían seguir para obtener el máximo beneficio de este comercio en el largo plazo.

\subsubsection{Evolución de la composición de exportaciones e importaciones}

Como ha sido mencionado en el transcurso de esta investigación, es a partir de la última década del siglo XX que en El Salvador se inició la implementación de políticas económicas, que se han traducido en cambios de la composición de exportaciones e importaciones.

En términos de la estructura de exportaciones, la categoría denominada como exportaciones tradicionales pasó de tener una participación de cerca de un $71 \%$ - en promedio- para inicios de la década de los ochenta a un promedio del $6 \%$ en el primer quinquenio de la presente década. En una comparación similar, las exportaciones del rubro maquila únicamente participaban con un $10 \%$ en promedio para finales de los ochenta, cifra baja en contraste con la registrada para inicios de la década actual, en la que estas representan en promedio el $58 \%$ del total de las exportaciones.

Las importaciones, por su parte, no han variado significativamente en su composición, con la única excepción de la maquila, que, a diferencia de la década de los ochenta, sus importaciones eran casi nulas. Este rubro, sin embargo, comenzó a cobrar fuerza en el quinquenio comprendido por los años de 1991 a 1995 al representar el 11\%, tendencia que continuó para el transcurso de la década siguiente, Ilegando a duplicar el valor de su participación. No obstante, la tendencia antes mencionada se ha visto disminuida en los años de 2006 y 2007, ya que la maquila sólo llegó a representar en promedio el $15 \%$ del total del valor de importaciones. Para apreciar lo anterior, mostramos el detalle de la composición de las transacciones comerciales para $\mathrm{El}$ Salvador: 


\begin{tabular}{|c|c|c|c|c|c|c|c|c|c|c|c|}
\hline \multirow{8}{*}{ 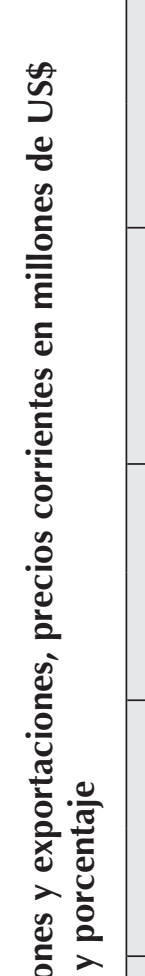 } & \multirow{2}{*}{ 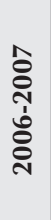 } & $\stackrel{\stackrel{\circ}{N}}{\stackrel{n}{n}}$ & $\begin{array}{l}\stackrel{0}{\circ} \\
\infty \\
\text { Ond }\end{array}$ & $\stackrel{\stackrel{0}{0}}{\circ}$ & $\stackrel{\circ}{\stackrel{0}{i n}}$ & $\stackrel{8}{8}$ & \multirow{2}{*}{ 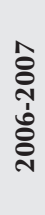 } & $\stackrel{\circ}{\wedge}$ & $\begin{array}{l}\stackrel{0}{\infty} \\
\stackrel{\infty}{+}\end{array}$ & $\stackrel{\stackrel{\circ}{\circ}}{\stackrel{\text { in }}{+}}$ & $\begin{array}{l}\stackrel{0}{\circ} \\
\text { ᄋ̊ }\end{array}$ \\
\hline & & $\begin{array}{l}\text { \& } \\
\text { i่ } \\
\text { రి } \\
\text { N }\end{array}$ & $\begin{array}{l}\text { ñ } \\
\stackrel{0}{\infty} \\
\infty \\
0\end{array}$ & $\begin{array}{l}0 \\
m \\
\infty \\
\infty \\
\stackrel{0}{\sim} \\
\leftarrow\end{array}$ & 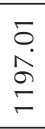 & $\begin{array}{l}\hat{b} \\
\tilde{N} \\
\frac{\infty}{\infty}\end{array}$ & & $\frac{\stackrel{q}{+}}{\dot{\sigma}}$ & 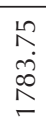 & 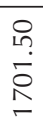 & 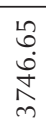 \\
\hline & \multirow{2}{*}{ 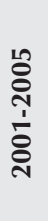 } & $\begin{array}{l}\stackrel{0}{\circ} \\
\stackrel{\sim}{\sim}\end{array}$ & 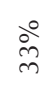 & $\stackrel{\circ}{0}$ & $\stackrel{\stackrel{\circ}{\sim}}{\sim}$ & $\stackrel{8}{8}$ & \multirow{2}{*}{ 䓍 } & o̊ & $\stackrel{\circ}{\stackrel{0}{n}}$ & 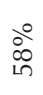 & $\stackrel{\circ}{\circ}$ \\
\hline & & 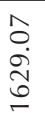 & 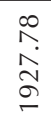 & $\begin{array}{l}\hat{c} \\
\text { i } \\
\stackrel{H}{\sigma}\end{array}$ & 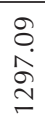 & $\begin{array}{l}\circ \\
\infty \\
\dot{0} \\
\stackrel{2}{\hat{~}} \\
\text { Ln }\end{array}$ & & 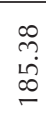 & $\begin{array}{l}0 \\
0 \\
\dot{0} \\
+ \\
\leftarrow\end{array}$ & 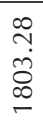 & $\begin{array}{l}\stackrel{0}{N} \\
\text { Ln } \\
\stackrel{n}{m}\end{array}$ \\
\hline & \multirow{2}{*}{$\begin{array}{l}\text { ठิ } \\
\text { సे } \\
\text { ঠे } \\
\text { बे }\end{array}$} & $\stackrel{\stackrel{\circ}{\sim}}{\stackrel{\circ}{v}}$ & $\stackrel{\stackrel{\circ}{+}}{\text { के }}$ & $\stackrel{\circ}{\circ}$ & $\frac{\circ}{\frac{0}{v}}$ & $\stackrel{\circ}{8}$ & \multirow{2}{*}{ 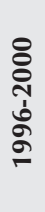 } & $\stackrel{\circ}{\stackrel{\circ}{-}}$ & $\stackrel{\circ}{\stackrel{\circ}{m}}$ & $\stackrel{\circ}{\circ}$ & $\stackrel{\circ}{\circ}$ \\
\hline & & $\begin{array}{l}\text { Jे } \\
\text { Ñ} \\
\hat{\sigma}\end{array}$ & $\begin{array}{l}\infty \\
\stackrel{n}{n} \\
\stackrel{0}{n}\end{array}$ & $\begin{array}{l}\text { 루 } \\
\dot{L} \\
\stackrel{0}{\infty}\end{array}$ & $\begin{array}{l}\stackrel{+}{\Lambda} \\
\stackrel{\sim}{L} \\
\infty\end{array}$ & 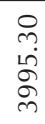 & & $\begin{array}{l}\stackrel{\circ}{\sigma} \\
\stackrel{\sigma}{+}\end{array}$ & 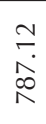 & $\begin{array}{l}0 \\
\stackrel{0}{0} \\
\stackrel{0}{1} \\
\div\end{array}$ & 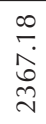 \\
\hline & \multirow{2}{*}{$\frac{\stackrel{L}{\sigma}}{\frac{\sigma}{\sigma}}$} & $\stackrel{\stackrel{\circ}{\sim}}{\stackrel{\circ}{v}}$ & 号 & $\stackrel{\stackrel{\circ}{\stackrel{\circ}{N}}}{ }$ & $\stackrel{\circ}{\frac{0}{\mp}}$ & ᄋ̊ & \multirow{2}{*}{$\frac{\frac{\operatorname{L}}{\sigma}}{\frac{1}{\sigma}}$} & $\begin{array}{l}\stackrel{0}{\circ} \\
\stackrel{\sim}{\sim}\end{array}$ & $\frac{\circ}{\dot{\gamma}}$ & $\frac{\circ}{m}$ & $\stackrel{\circ}{\circ}$ \\
\hline & & 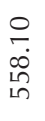 & 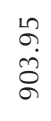 & $\begin{array}{l}\bar{N} \\
\text { L } \\
\text { L } \\
\end{array}$ & 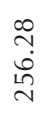 & 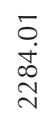 & & 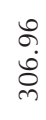 & $\begin{array}{l}\stackrel{P}{+} \\
\stackrel{f}{f}\end{array}$ & $\begin{array}{l}0 \\
+ \\
\stackrel{m}{m} \\
m\end{array}$ & $\begin{array}{l}\infty \\
\infty \\
\infty \\
\infty \\
0 \\
-1\end{array}$ \\
\hline 븜 & \multirow{2}{*}{ 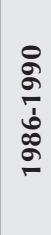 } & $\stackrel{\circ}{\stackrel{\circ}{人}}$ & $\stackrel{\circ}{\circ}$ & $\stackrel{\stackrel{0}{\nu}}{\stackrel{\nu}{v}}$ & $\stackrel{\circ}{\circ}$ & ஓ̊ & \multirow{2}{*}{$\frac{\text { के }}{\frac{\sigma}{b}}$} & $\stackrel{\circ}{\stackrel{0}{\hat{R}}}$ & $\stackrel{\circ}{m}$ & @̊ & ஓ̊̊ \\
\hline 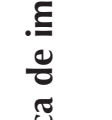 & & $\begin{array}{l}\text { \&े } \\
\text { నे } \\
\text { ปे }\end{array}$ & 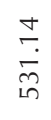 & $\begin{array}{l}\stackrel{N}{N} \\
\infty \\
\stackrel{+}{\sim}\end{array}$ & $\stackrel{\circ}{\circ}$ & 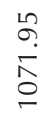 & & $\begin{array}{l}\stackrel{0}{\llcorner} \\
+ \\
\infty \\
m \\
m\end{array}$ & 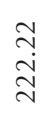 & $\begin{array}{l}\text { ठి } \\
\text { Lீ }\end{array}$ & 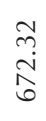 \\
\hline '̄ & \multirow{2}{*}{ 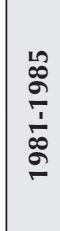 } & 吕 & $\begin{array}{l}\stackrel{0}{\circ} \\
\infty \\
\stackrel{\infty}{n}\end{array}$ & $\stackrel{\circ}{\stackrel{0}{r}}$ & \&̊ & ஓ̊ & \multirow{2}{*}{$\frac{\stackrel{L}{\infty}}{\frac{\sigma}{1}}$} & $\frac{\circ}{\pi}$ & $\stackrel{\circ}{\stackrel{\circ}{~}}$ & $\dot{8}^{\circ}$ & $\stackrel{\circ}{8}$ \\
\hline \multirow{2}{*}{ 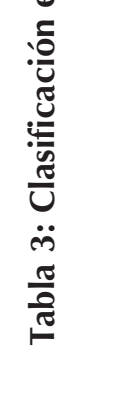 } & & $\stackrel{+}{\stackrel{\sim}{N}}$ & $\begin{array}{l}\stackrel{2}{+} \\
\stackrel{+}{+}\end{array}$ & $\begin{array}{l}\hat{N} \\
\check{E}\end{array}$ & $\stackrel{\circ}{\circ}$ & $\begin{array}{l}0 \\
\dot{+} \\
\text { ñ }\end{array}$ & & $\begin{array}{l}0 \\
\text { ம் } \\
\text { Ln }\end{array}$ & $\frac{n}{n}$ & $\stackrel{\circ}{\circ}$ & $\stackrel{n}{\stackrel{n}{N}}$ \\
\hline & 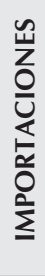 & 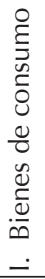 & 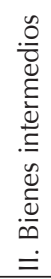 & 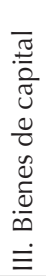 & $\begin{array}{l}\frac{\pi}{\bar{J}} \\
\frac{\pi}{2} \\
\sum \\
\geq\end{array}$ & $\underset{1}{\underline{\sigma}}$ & 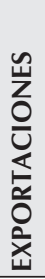 & 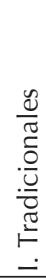 & 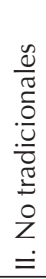 & $\begin{array}{l}\frac{\pi}{\equiv} \\
\frac{\pi}{0} \\
\sum \\
\equiv\end{array}$ & $\underset{上}{\stackrel{2}{0}}$ \\
\hline
\end{tabular}


De las cifras anteriores, inferimos que los cambios experimentados en la elasticidad ingreso de exportaciones e importaciones que surgen de comparar el período anterior al de liberalización y apertura comercial, coinciden con cambios en la composición de las mismas. Dichas variantes consistieron en la paulatina transición de basar las exportaciones en productos agrícolas a hacerlo ahora en bienes manufacturados, y en importaciones actualmente menos limitadas por las barreras arancelarias, a lo que además se suma el ya mencionado incremento de importaciones de maquila.

Es notorio como la composición de exportaciones dejó de ser en su mayoría primario-exportadoras y ahora se basa en la elaboración de productos con un aparente mayor valor agregado, como lo es la manufactura - de acuerdo con lo expuesto por Kaldor-. Sin embargo, según Cabrera et al. (2005), la maquila en nuestro país genera un efecto multiplicador bajo, debido a su estructura productiva dependiente de importaciones de materias primas y bienes de capital, que aun se caracteriza por su bajo contenido tecnológico y utilización intensiva de mano de obra poco calificada maquila textil-; como resultado de un limitado desarrollo de la innovación y difusión tecnológica de las empresas, lo que ha restringido la posibilidad de generar incrementos continuos en la productividad de los factores de producción. Estas li- mitantes son reflejadas en la reducción de salarios o el aumento de los costos de producción, que en caso del último escenario, se traduce en una pérdida de competitividad de la producción nacional con respecto al resto del mundo.

\subsubsection{El deterioro de los términos de intercambio}

Dado que las elasticidades ingreso de las demandas de exportaciones e importaciones dependen en gran medida del tipo de bienes que se transe, los cuales a su vez poseen tal relevancia por los niveles de precios relativos con los que se pueda comerciar, resulta de suma importancia estudiar la evolución que han experimentado los términos de intercambio en nuestra economía. En la medida en que observemos dicha relación entenderemos la influencia que ejercen los precios de los productos transados en los saldos de balanza comercial y seremos capaces de determinar el tipo de efecto que implica la variación de los precios sobre el intercambio comercial de nuestro país con el exterior, ya que el deterioro de los términos de intercambio repercute directamente en el ingreso nacional y su distribución (De León y Noyola, 2005).

Los términos de intercambio son expresados a través de un índice que se construye mediante el cálculo de la razón del índice de precios de las exportaciones y el índice de precio de las importaciones ${ }^{8}$ 
$\left(\frac{\mathrm{P}_{x}}{\mathrm{IP}_{\mathrm{X}}}\right)\left(\frac{\mathrm{P}_{\mathrm{X}}}{\mathrm{I} \mathrm{P}_{\mathrm{y}}}\right)$. Con esto se logra medir la variación del poder de compra de una unidad física de exportaciones, en términos de importaciones. Es decir, un aumento del Índice de Términos de Intercambio (ITI) para un período determinando significa que los precios de las exportaciones aumentan más o caen menos que los precios de importaciones en ese período, y viceversa.

Para el transcurso de los últimos años El Salvador ha experimentado una notoria tendencia al deterioro de los términos de intercambio, lo que en consecuencia se traduce en una disminución del poder de compra del ingreso real del país. Esta tendencia al deterioro de los términos de intercambio se aprecia en el Gráfico 5:

\section{Gráfico 5: Términos de intercambio e índices de precios de exportaciones e importaciones 1995-2007}

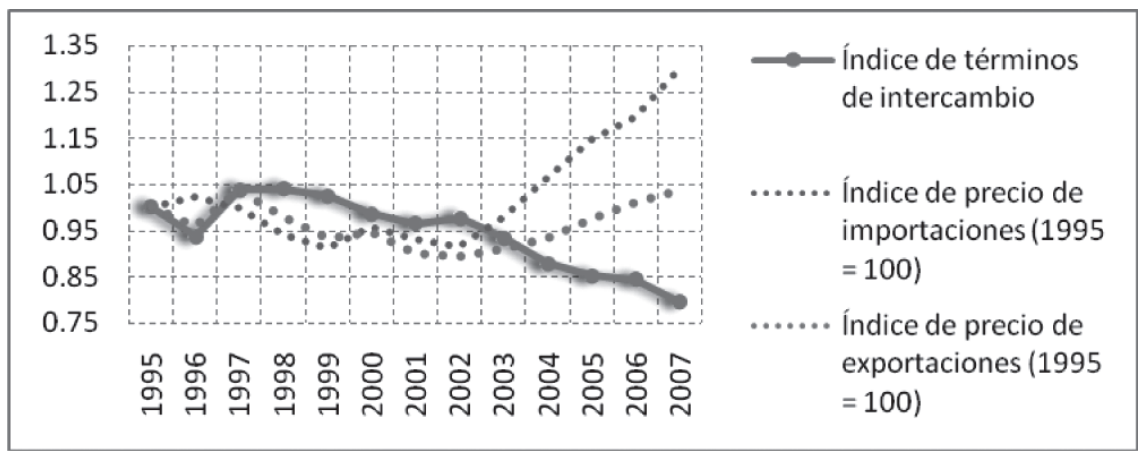

Fuente: Elaboración propia con base a información del BM: World Development Indicators y BCR de El Salvador.

Los términos de intercambio están siendo afectados en forma negativa por los bajos precios de las exportaciones tradicionales y los altos precios de las importaciones esta última en mayor medida. Para el caso de las exportaciones, sus precios se han mostrado afectados mayormente por la caída del precio del café, esta debido a la mayor producción de Vietnam y otros nuevos oferentes, así como a los aumentos en la capacidad productiva de Brasil. Así mismo, han sido perjudicados por la caída del precio del azúcar, producto de las abundantes cosechas de este último país mencionado. Mientras que para las importaciones se registró una subida en sus precios, dentro de ellos se destacan como los más influyentes los correspondientes a combustibles y lubricantes (De León y Noyola, 2005).

El deterioro de los términos de intercambio, fruto de las variaciones adversas en los precios, se ha traducido en un mayor déficit comercial, 
ya que a pesar que los volúmenes de exportación han aumentado en los últimos años (BCR, 2008a), el precio de estas no ha aumentado en una mayor proporción al de los precios de las importaciones, lo que erosiona la capacidad de adquisición de las exportaciones, en término de su contraparte, generando de esta forma un estructural crecimiento del déficit comercial.

Poder de compra de las exportaciones y cobertura que brinda a las importaciones

Ante la presencia del deterioro de los términos de intercambio, resulta importante contar con un estimador para la pérdida de poder adquisitivo de las exportaciones que esto conlleva. Se ha utilizado el indicador del poder de compra de las exportaciones $\left(\mathrm{PC}_{\mathrm{X}}\right)(\mathrm{PC} \mathrm{X})$, constituido por la razón del valor de las exportaciones corrientes en dólares y el índice de precios de las importaciones, multiplicado por cien $\left(\frac{\mathrm{X}}{\mathrm{IP}_{\mathrm{M}}} 100\right)\left(\frac{\mathrm{X}}{\mathrm{IP}} 100\right)$. Este indicador permite estimar la cantidad de unidades físicas de importaciones valoradas a precios de un año base, que se pueden adquirir efectivamente con el valor de las exportaciones realizadas.

Además nos auxiliamos del indicador de la cobertura de las importaciones, que es calculado a través del ratio de $P C_{X} P C_{X}$ e importaciones a precios corrientes $\left(\frac{\mathrm{PC}_{\mathrm{x}}}{\mathrm{M}}\right)$ $\left(\frac{\mathrm{PC}_{\mathrm{x}}}{\mathrm{M}}\right)$, lo que denota el porcentaje de importaciones que se cubre con este poder de compra. La evolución de ambos indicadores es contrastada en el gráfico siguiente:

\section{Gráfico 6: Poder de compra de las exportaciones $\left(\mathrm{IP}_{M} 1995=100\right)$ 1995-2007}

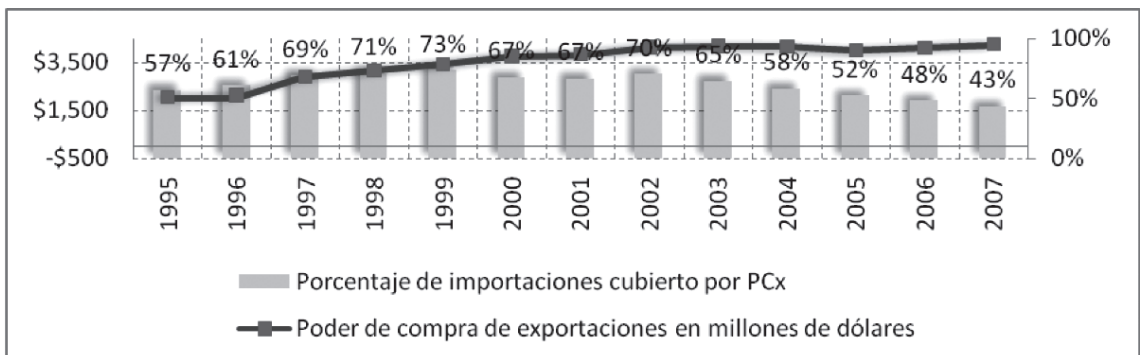

Fuente: Elaboración propia con base a información del BM: World Development Indicators y BCR de El Salvador.

Se observa un progresivo aumento en el poder de compra de las exportaciones, sin embargo, es a partir del año 2002 que se inicia un estancamiento del mismo, el cual persiste hasta el año 2007. Dicho enfriamiento, según De León y Noyola (2005), se debe al aumento progresivo en el índice de precio de las importaciones, unido a un lento 
crecimiento de las exportaciones. En donde las importaciones crecen a una mayor proporción que el poder de compra de las exportaciones, efecto atribuido a factores como la apertura de la economía -frente a economías más desarrolladas- y a un mayor gasto interno promovido por el incremento de las remesas familiares.

Por otro lado, podemos apreciar una disminución en el porcentaje de importaciones cubiertas por el poder de compra de las exportaciones. Para 2002, este registró un $70 \%$ de importaciones cubiertas, y a partir de ese punto comenzó a disminuir progresivamente, a tal grado que estas ni siquiera llegaron a cubrir la mitad de las importaciones del año 2006. Dicha tendencia se traduce en una pérdida de la contribución de las exportaciones para mejorar el déficit comercial, ya que su crecimiento no está acompañado de un aumento en su capacidad adquisitiva, Ilevándonos a la interrogante: ¿Qué tan beneficioso ha sido el intercambio entre nuestro país y el resto del mundo?

Ganancia o pérdida del intercambio

En El Salvador, las exportaciones se encuentran altamente concentradas en pocos productos, lo que trae como consecuencia que las variaciones en los términos de intercambio sean muy amplias, permitiendo de esta forma la existencia de grandes diferencias entre el producto interno y su poder de compra. De ello se desprende la relevancia de contar con un aproximado de la ganancia o pérdida que surge del intercambio, estimación que puede ser realizada a través de la diferencia de la exportaciones deflactadas con los precios de importación $\mathrm{Y}$ de exportación $\left[\frac{\mathrm{X}}{\mathrm{IP}}-\frac{\mathrm{X}}{\mathrm{IP}}\right]$ $\left[\frac{X}{I_{M}}-\frac{X}{I_{X}}\right]$ (De León y Noyola, 2005).

Esta ganancia o pérdida, a su vez se encuentra influenciada por los términos de intercambio, ya que un aumento en estos se traduce en la posibilidad de adquirir un mayor nivel de importaciones con el mismo volumen de exportaciones, u obtener la misma cantidad de importaciones con un volumen menor de exportaciones. Es decir, un aumento del ITI repercute en un incremento en el Ingreso Interno Bruto Real (IIBR)

En el gráfico 7 podemos observar los resultados obtenidos de calcular la ganancia o pérdida del intercambio, donde puede apreciarse un sistemático detrimento en el poder de compra del PIB para los últimos años. 
Gráfico 7: Ganancia o pérdida del intercambio comercial como porcentaje del PIB a precios corrientes 1995-2007

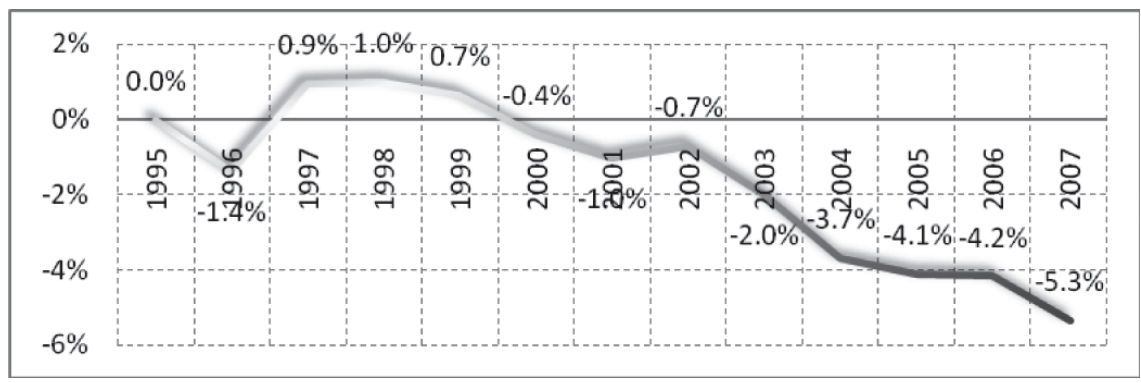

Fuente: Elaboración propia con base a información del BM: World Development Indicators y BCR de El Salvador.

Durante el período comprendido por los años de 1997 a 1999 se obtuvieron ganancias en el intercambio, las cuales representaron en sus respectivos años alrededor de $1 \%$ del PIB. Sin embargo, es a partir de ese punto que con el aumento del precio de las importaciones se inició una disminución significativa en el poder de compra, efecto que trajo como resultado que la pérdida representara en 2007 un 5.3\% del PIB. Esto es alarmante, por cuanto la pérdida del último año representa cinco veces lo que representó la mayor ganancia de un año para el período inicialmente mencionado.

\section{Conclusiones}

Con el drástico proceso de liberalización y apertura comercial a raíz de la implementación de los $\mathrm{PAE}$, se dieron diversos cambios en los volúmenes de transacciones comerciales que sostiene nuestro país con el resto del mundo. Al ser los Estados Unidos el socio más representativo en términos de estas transacciones, resulta lógico pensar en la existencia de una significativa relación entre su crecimiento y el nuestro.

La relación de crecimiento de ambos países ha estado históricamente influenciada por la razón de las elasticidades ingreso de la demanda de exportaciones e importaciones, la cual ha sufrido una evolución adversa en el paso del período de preapertura al de liberalización y apertura comercial, congruente con el cambio en la composición de exportaciones e importaciones, acompañado del deterioro de los términos de intercambio experimentado en el país en los últimos años.

La ratio de elasticidades, a pesar de haber logrado mantenerse levemente superior a la unidad y por consecuencia haber obtenido tasas de crecimiento mayores a las de Estados Unidos, no ha permitido superar el crecimiento promedio experimentado en el período de preapertura, así como tampoco ha satisfecho las expectativas generadas por los organismos internacio- 
nales, en términos de crecimiento económico.

A finales de la década de los ochenta, el requisito primordial que El Salvador, al igual que otros países de América Latina, enfrentó para acceder a los préstamos que los Organismos Internacionales otorgaron, fue la implementación de los PEE y PAE. De este último destacamos como uno de los componentes principales la liberalización y apertura de nuestros mercados. Así, dicho proyecto surtió efecto en cuanto que, para los años siguientes, favoreció el incremento de los volúmenes de transacciones comerciales que efectúa nuestro país en los mercados internacionales. Estos cambios han transformado estructuralmente a la economía salvadoreña en lo que se refiere a sus patrones de consumo y producción.

El comercio internacional, aunque no es el único factor, influye directamente en el crecimiento económico de largo plazo de los países, El Salvador no es la excepción ya que por ejemplo con Estados Unidos, su principal socio comercial, mantiene una relación estrecha de crecimiento económico de largo plazo. Esto, debido a que dichos crecimientos se enlazan a través de los patrones comerciales con los que operan los países involucrados, aunque, al existir asimetrías, no puede decirse que ambas partes se afecten mutuamente en la misma medida.

El proceso de apertura comercial en nuestro país, no solamente ha fracasado en lo que concierne al alivio de la tendencia deficitaria en los saldos comerciales, sino que contrario a lo último, ha contribuido a profundizar dicha problemática al mostrar saldos negativos nunca antes registrados en los últimos cincuenta años. Esta tendencia resulta insostenible en el largo plazo, dado que no se obtienen las divisas necesarias para mantener el actual nivel de importaciones. Por otro lado, el intercambio comercial, evaluado en el indicador de ganancia o pérdida del mismo, ha generado para esta última década en su mayoría pérdidas con una clara tendencia al incremento. Ambos resultados refuerzan la idea que la mencionada apertura no ha conllevado al crecimiento económico deseado.

Fruto de las variaciones adversas de los precios, los términos de intercambio se han visto deteriorados, generando un aumento en el déficit comercial, ya que a pesar de aumentos en los volúmenes de exportaciones, sus precios no han registrado aumentos en la misma proporción al precio de las importaciones, generando una tendencia a la disminución en la capacidad adquisitiva de las exportaciones.

Se ha mostrado que la ley de Thirlwall se cumple para el caso de El Salvador, dado que se comprobó que la razón de crecimiento de nuestro país y Estados Unidos -este último como aproximado del resto del mundo- sigue una tendencia muy cercana a la ratio de 
elasticidades ingreso de demanda de exportaciones e importaciones. La ratio en cuestión se ha visto deteriorada durante el período de apertura comercial en comparación con el de preapertura, lo que respalda que las políticas de liberalización aplicadas en El Salvador no han alcanzado las expectativas en lo que se refiere a mejorar el desempeño económico, más bien, la apertura comercial al haber reducido el ratio de elasticidades ha debilitado la influencia exterior sobre el crecimiento económico nacional.

Las elasticidades ingreso de demanda de exportaciones e importaciones están directamente influenciadas por el tipo de bienes que se transan, por ello las políticas comerciales deben estar enfocadas a modificar dichas elasticidades de manera favorable. Esto implica expandir la brecha entre las mismas — superioridad de la elasticidad de exportaciones-y así encontrarnos en una mejor situación con respecto al resto del mundo en términos de crecimiento económico.

\section{Bibliografía}

Ábrego, L., (1991) "Reforma comercial y reconversión industrial en El Salvador" en Realidad Económico-Social. Año IV, número 22, Julio-Agosto 1991, pp. 469-490.

Acevedo, C. (2003). "La experiencia de crecimiento económico en El Salvador durante el siglo
El proceso liberalización externa de El Salvador, el cual caracterizamos con aspectos como la eliminación de controles de precios, promoción de ciertas exportaciones, reducción de barreras arancelarias y tratados comerciales. Estas políticas no han tenido en todo su accionar como criterio primordial el incentivar e incluir en las negociaciones canastas de bienes que posean altas elasticidades ingreso de la demanda de exportaciones en comparación con las de importaciones, como resultado de ello, se ha visto restringido el beneficio potencial de las negociaciones comerciales.

Todas las afirmaciones anteriores nos llevan a decir que las estructuras de exportación e importación son factores determinantes en la relación de apertura comercial y crecimiento económico en El Salvador, es por ello que las bajas tasas de crecimiento son, en gran medida, debidas a la existente tendencia estructural al deterioro de la balanza comercial.

$X X^{\prime \prime}$. Serie de Estudios Económicos y Sectoriales. San Salvador. Banco Interamericano de Desarrollo (BID).

Banco Central de Reserva de El Salvador, (2002). "El tratado de libre comercio entre El Salvador y Los Estados Unidos". Boletín Económico. [En línea] San Salvador, BCR. Disponible en: http://www.bcr.gob.sv/publicaciones/boletin_economico/ 


boletin_20020708_c_ensayo_-
tlc_es_usa.pdf [Consultado el 2
de julio de 2008].
Banco Central de Reserva de El
Salvador, (2007). "Ley de Inte-
gración Monetaria". [En línea]
San Salvador, BCR. Disponible
en: http://www.bcr.gob.sv/inte-
gracion/ley.html [Consultado el
4 de julio de 2008].
Banco Central de Reserva de El Sal-
vador, (2008a). "El Tratado de
Libre Comercio entre El Salva-
dor y los Estados Unidos". [En
línea] San Salvador, BCR. Dis-
ponible en: http://www.bcr.gob.
sv/publicaciones/boletin_econo-
mico/boletin_20020708_c_en-
sayo_tlc_es_usa.pdf [Consulta-
do el 1 de julio de 2008].
Banco Central de Reserva de El
Salvador, (2008b). Series esta-
dísticas. [En línea] San Salva-
dor, BCR. Disponible en: http://
www.bcr.gob.sv/estadisticas/
series_estadisticas.html [Con-
sultado el 4 de julio de 2008].
Banco Mundial (2003), "El Salvador
creciendo en el nuevo milenio"
[En línea], Estados Unidos. BM.
Disponible en: http://wbln0018.
worldbank.org/lac/lacinfoclient.
nsf/d29684951174975c852567
35007fef12/e774c32dfcfcffe385
256e7e0072db0a/\$FILE/El\%20
Salvador_Creciendo\%20en\%20
el\%20Nuevo\%20Milenio\%20
(2).pdf [Consultado el 6 de julio
de 2008].

Banco Mundial (2007). "Indicadores mundiales de desarrollo". [En línea] Estados Unidos, Disponible en: http://ddpext.worldbank.org/ext/ DDPQQ/member.do?method= getMembers \&userid $=1$ \&query Id135 [Consultado el 4 de julio de 2008].

Bonilla, E. (1990). Los PAE y la estabilización económica en Centroamérica. Washington D.C. Banco Mundial.

Cabrera, O.; Fuentes, J. y H. de Morales, (2005). Hechos estilizados en el crecimiento económico de El Salvador, 1978-2004: Una propuesta de acciones de política económica en el corto y mediano plazo. Documentos de trabajo No. 2005-02. San Salvador, Banco Central de Reserva.

Cámara Americana de Comercio de El Salvador (2008). "TLC con Panamá", Dirección de Administración de Tratados Comerciales. AmCham. [En línea]. San Salvador, Disponible en Internet en: http://www.amchamsal. $\mathrm{com} /$ ?cat=1035 [Consultado el 5 de julio de 2008].

Cano, C. et al (2004). "Diferencias y similitudes en las teorías del crecimiento económico". [En línea] Número. 44, diciembre de 2004, EUMED, disponible en: http://www.eumed.net/cursecon/libreria/2004/mca/mca. htm [Consultado el 31 de mayo de 2008]. 
Comisión Nacional de la Micro y Pequeña Empresa, (2008). "TLC El Salvador - México: Antecedentes, características, estructura y beneficios". [En línea] San Salvador, CONAMYPE, Disponible en: http://www.conamype.gob.sv/biblio/pdf/0279. pdf [Consultado el 28 de Junio de 2008].

Corte Suprema de Justicia de El Salvador, (1990). "Ley de reactivación de las exportaciones". San Salvador, Ministerio de Economía.

De la Rosa, J., (2006). "Dos enfoques teóricos sobre el proceso de crecimiento económico, con énfasis en las exportaciones manufactureras" en Análisis Económico [En línea], Volumen 21, Número 48, tercer cuatrimestre, México, Universidad Autónoma Metropolitana Azcapotzalco, disponible en: http://redalyc. uaemex.mx/redalyc/src/inicio/ ArtPdfRed.jsp? iCve $=41304806$ [Consultado el 18 de Mayo de 2008].

De León, C. y A. Noyola, (2005). Índice de términos de intercambio en El Salvador: 1995-2004. Documentos ocasionales, 200502. San Salvador, Banco Central de Reserva.

Del Cid, R. y R, Mendoza, (1990). Industrialización y desarrollo tecnológico en El Salvador 1950-1987. Tesis de Licenciatura. San Salvador, Departamento de Economía, Universidad
Centroamericana "José Simeón Cañas".

Department of Defense, (2006). "Department of Defense: Budget" DefenseLink. [En línea] Washington D.C., Disponible en: http://www.defenselink.mil/ news/Feb2006/d20060206slides.pdf [Consultado el 3 de julio de 2008].

Durán, M.; Martínez, F. y J. Oporto. (1995). Impacto de la apertura comercial en la industria manufacturera de El Salvador: Ramas textil y alimentaria (19891994)" Tesis de Licenciatura. San Salvador, Departamento de Economía, Universidad Centroamericana "José Simeón Cañas".

Fundación Salvadoreña para el Desarrollo Económico y Social (1998). "Evolución y efectos de la desgravación arancelaria". Informe Semanal, № 4, febrero de 1995, San Salvador, FUSADES.

Fundación Salvadoreña para el Desarrollo Económico y Social (2003). La necesidad de un nuevo modelo económico para El Salvador: Lineamientos generales de una estrategia. Segunda Edición, San Salvador. FUSADES.

González, R. (2008). "América Latina: balance económico de dos décadas". Red de Estudios de la economía mundial [En línea] México, Disponible en: http:// www.redem.buap.mx/semgonzalez.htm [Consultado el 5 de julio de 2008]. 
Guerrero, C. (2003). Modelo de crecimiento económico restringido por la balanza de pagos: evidencia para México, 19402000. [En línea] Departamento de Economía, Tecnológico de Monterrey, México disponible en: www.asepelt.org/ficheros/ File/Anales/2004\%20-\%20Leon/ comunicaciones/ Guerrero.doc [Consultado el 14 de mayo de 2008].

Havemann, J. (2007). "War Cost are Hitting Historic Proportions" en CommonDreams. org. 15 de enero de 2007. [En línea] Los Ángeles, NewsCenter, Disponible en: http://www. commondreams.org/headlines07/0115-05.htm [Consultado el 5 de julio de 2008].

Hounie, A. et al (1999) "La CEPAL y las nuevas teorías del crecimiento" en Revista de la CEPAL. $N^{\circ}$ 68, agosto de 1999, pp. 7-33.

Marichal, C. (2003). "Ciclos y crisis de la deuda externa en América Latina". Comité para la Anulación de la Deuda Externa del Tercer Mundo. [En línea] Lieja, Bélgica. Disponible en: http://www.cadtm.org/article. php3?id_article $=352$ [Consultado el 4 de julio de 2008].

Ministerio de Economía de El Salvador (2007). "Documento explicativo del Tratado de Libre Comercio entre las repúblicas de El Salvador y Honduras con la república de Taiwán" [En línea], San Salvador, MINEC. Disponible en: http://www. minec.gob.sv/tlc/tlc_web/pdf/ taiwan/DOC_EXPLICATIVO_ TLC_TAIWAN.pdf [Consultado el $1^{\circ}$ de julio de 2008].

Ministerio de Economía de El Salvador, (2002). "El Salvador barre República Dominicana". Dirección de Comunicaciones y R.R.P.P. MINEC. [En línea]. San Salvador, Disponible en Internet en: http://www.minec.gob. sv/default.asp?id=33\&mnu=31 [Consultado el $1^{\circ}$ de julio de 2008].

Ministerio de Economía de El Salvador, (2004). "Documento explicativo del TLC entre El Salvador y Estados Unidos". Dirección de Política Comercial, MINEC. [En línea], San Salvador, Disponible en: http://www.minec.gob.sv/MEDIA/downloads/ CAFTA\%20Documento\%20 Explicativo.pdf [Consultado el 28 de junio de 2008].

Ministerio de Economía de El Salvador, (2008). "Tratado de Libre Comercio El Salvador-Chile". Dirección de Política Comercial. MINEC. [En línea]. San Salvador, Disponible en Internet en: http://www.conamype.gob. sv/biblio/pdf/0292.pdf [Consultado el 3 de julio de 2008].

Montoya, A., (2000). Apuntes de desarrollo económico. San Salvador, Editores Críticos. 
Moreno-Brid J., (1998/1999) "On Capital Flows and the Balance of Payments Constrained Growth Model", Journal of Post Keynesian Economics. Volumen 21, No 2, Invierno 1998/1999, pp. $283-298$

Ocampo. J., (1988). Economía poskeynesiana. México, Fondo de Cultura Económica.

Pérez, A. (1995) Deuda externa de América Latina: Balance de una década. 1980-1990. Universidad de La Rioja. [En línea] España, Disponible en: http://dialnet.unirioja.es/servlet/ articulo?codigo=164225 [Consultado el 4 de julio de 2008].

Prebisch, R., (1956). Introducción a Keynes. Tercera edición. México, Fondo de Cultura Económica.

Prebisch, R., (1983). Cinco etapas de mi pensamiento sobre el desarrollo. México. Fondo de Cultura Económica.

Programa de las Naciones Unidas para el Desarrollo (2001). Informe de Desarrollo Humano: El Salvador. San Salvador.

Promoviendo Inversión en El Salvador, (2008). "Acceso a Mercados". PROESA, [En línea] San Salvador, Disponible en: http:// www.proesa.com.sv/spn/accesodemercados.html [Consultado el 26 de junio de 2008].

Rivera, R., (2000). La economía salvadoreña al final del siglo:
Desafíos para el futuro. San Salvador, FLACSO.

Rodríguez, J., (2003). "La economía laboral en el período clásico de la historia del pensamiento económico". EUMED [En línea] Tesis 41, España, Universidad de Valladolid, disponible en: http://www.eumed.net/tesis/ jcrc/ [Consultado el 21 de abril de 2008].

Ruthrauff, J. (1997). Una introducción al Banco Mundial, Banco Interamericano de Desarrollo, y Fondo Monetario Internacional. Maryland. Centro para la Educación Democrática.

Salvatore, D., (1998). Economía internacional. Cuarta edición, traducción por Gladys Arango Medina, Colombia, Editorial McGraw-Hill.

SAPRIN (2005). Ajuste estructural. Informe SAPRI: Las políticas de ajuste estructural en las raíces de la crisis económica, la pobreza y la desigualdad. Nueva York, Editorial Intermón Oxfam.

Segovia, A. (2002). Transformación estructural y reforma económica en El Salvador. Guatemala, F\&G Editores.

Thirlwall, A., (2003). La naturaleza del crecimiento económico. Un marco alternativo para comprender el desempeño de las naciones. Traducción por Carlos Absalón. México, Fondo de Cultura Económica. 


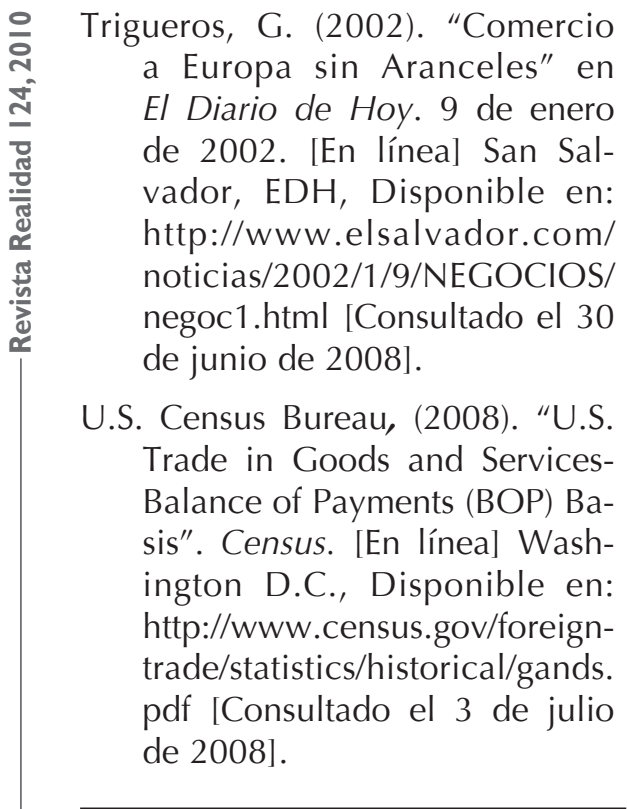

\section{Notas}

1 Debe tenerse presente que sólo contamos con información que data desde el año 1960, y que desagregamos los períodos por décadas para tener una información más detallada.

2 Cálculo realizado como

TAMC $=\left[\left(\frac{g_{\text {gnas }}}{g_{\text {sutas }}}\right)^{\frac{2}{2}}-1\right] \times 100$

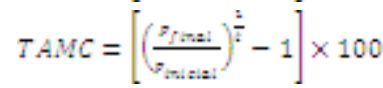

3 La comparación no se realiza con el ánimo de elogiar al modelo de sustitución de importaciones en detrimento del de economía de mercado o viceversa, sino como un contraste que sirva de parámetro para el cuestionamiento de los beneficios derivados de la apertura comercial.
Vergara, A. (2005). "América Latina entre sombras y luces". Eumed. [En línea] Málaga, Disponible en: http://www.eumed.net/libros/2005/av/ [Consultado el 4 de julio de 2008].

Williamson, J. (1999). "Lo que Washington quiere decir cuando se refiere a reformas de las políticas económicas". Caixa [En línea] 1999, Barcelona, Disponible en: http://www.pdf. lacaixa.comunicacions.com/ee/ esp/ee15_c3_esp.pdf [Consultado el 8 de Junio de 2008].

4 Ambas series de datos fueron sometidas a pruebas de estacionalidad de raíces unitarias, con lo que mostraron poseer propiedades estacionarias, ya que es posible referirse a dichas tasas de crecimiento como la primera diferencia del PIB de El Salvador y el PIB de Estados Unidos en logaritmo natural.

5 Se realizaron pruebas de normalidad de los errores en los VAR, de lo que se obtuvo homoscedasticidad.

6 La "década perdida" no fue tomada en cuenta en la estimación de las elasticidades por dos razones: a) El Salvador se encontraba en un proceso de transición de modelo y por b) la presión que el conflicto armado interno generó. 
7 El modelo de Thirlwall da preponderancia a las elasticidades ingreso. Sin embargo, también permite obtener las elasticidades precio, que podrían ser utilizadas para estudios posteriores.

8 Los índices de precios son indicadores de la evolución en el tiempo de los precios de un conjunto de bienes y servicios. La metodología utilizada para el cálculo de estos puede ser consultada en De León y Noyola (2005).

$\mathrm{El}$ ingreso interno bruto (en precios constantes) se obtiene sumando el PIB y el ajuste en la relación de intercambio, es decir sumarle al PIB la ganancia o pérdida del intercambio comercial (BM, 2008). 